\title{
Commentary: The unspoken truth about ease of use
}

\author{
Eric E. Roselli, MD, and Rakesh M. Suri, MD, DPhil
}

\footnotetext{
From the Aortic Valve Center, Department of Thoracic and Cardiovascular Surgery, Heart and Vascular Institute, Cleveland Clinic, Cleveland, Ohio; and Cleveland Clinic, Abu Dhabi, United Arab Emirates.

Disclosures: Dr Roselli receives honoraria for consulting and speaking from LivaNova and Edwards Lifesciences. Dr Suri has nothing to disclose with regard to commercial support.

Received for publication March 11,2019; accepted for publication March 11, 2019; available ahead of print April $30,2019$.

Address for reprints: Eric E. Roselli, MD, Department of Thoracic and Cardiovascular Surgery, Cleveland Clinic, 9500 Euclid Ave, Desk J4-1, Cleveland, OH 44195 (E-mail: roselle@ ccf.org).

J Thorac Cardiovasc Surg 2020;159:443-502

$0022-5223 / \$ 36.00$

Copyright (C) 2019 Published by Elsevier Inc. on behalf of The American Association for Thoracic Surgery https://doi.org/10.1016/j.jtcvs.2019.03.045
}

In valve surgery, choosing a prosthesis is one of the most important and complex decisions that we make. It requires a thorough understanding of the patient's anatomy, pathology, physiology, and preference regarding anticoagulation and lifestyle. It requires an appreciation for the patient's prognosis predicted by age and comorbidities. It also requires knowledge of one's own surgical outcomes and experience with various techniques and devices.

In the current era of treating patients with advanced aortic valve disease, we have more aortic valve replacement options than ever: mechanical valves requiring lower doses of anticoagulation; pulmonary autograft (Ross); native pericardium (Ozaki); bioprostheses with or without stents, of porcine or bovine origin, delivered transcatheter (TAVR) or through minimally invasive approaches (partial sternotomy or right thoracotomy); and now, self-anchoring prostheses. With so many options, it is our duty to tailor the best choice to each individual patient, and that requires an appreciation for the interplay among many variables.

Frequently, device manufacturers will enumerate the characteristics of a valve, especially when developing new products. At the top of this list is "ease of use," a feature not often discussed in academic literature. Or is it? A PubMed search for "learning curve and cardiac surgery" yields 1095 items. When we include variables such as intraoperative intervals (eg, crossclamp and bypass times) and perform analyses to assess a learning curve, are we not studying ease-of-use features of a technology? Novel sutureless (Perceval; LivaNova PLC, London, United Kingdom) and rapid-deployment (Intuity; Edwards Lifesciences, Irvine, Calif) valves capitalize on the importance of ease of use, and both are now available in the United States. $^{1,2}$

In their article published in this issue of the Journal, D'Onofrio and colleagues ${ }^{3}$ have compared outcomes in patients receiving these self-anchoring valves in a real-world European experience (Intuity data from an Italian registry and Perceval data from 3 other centers). Greedy-matching on 16 variables modeled for receiving an Intuity valve

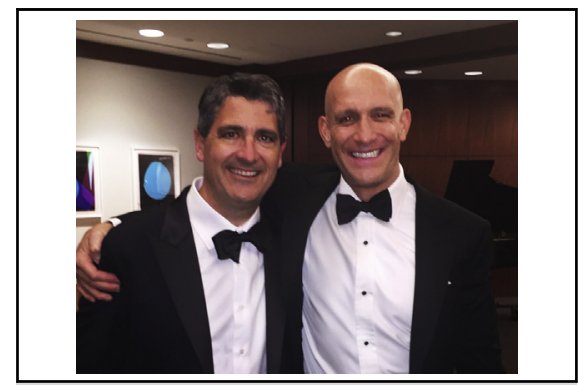

Eric E. Roselli, MD (left), and Rakesh M. Suri, MD, DPhil (right)

Central Message

New self-anchoring aortic valves provide an easier to use surgical replacement withou compromising procedural quality or potential additional benefits to patients.

See Article page 432 . yielded 117 matched pairs. This is only 34\% of possible matches, but the Perceval was consistently implanted in higher-risk patients. Valve Academic Research Consortium definitions were used. Primary outcomes were mortality and permanent pacemaker, and secondary outcomes were surgical times and hemodynamics. Thirty-day mortalities were similar between groups and compared favorably with predicted risk. Although they were not compared with standard sutured surgical aortic valve replacement, both self-anchoring valves provided the benefit of considerably shorter crossclamp times compared with all aortic devices in the Society of Thoracic Surgeons database. ${ }^{3}$ The Perceval saved 20 more minutes than the Intuity, 10 minutes for isolated aortic valve replacement, and 15 minutes for a minimally invasive approach.

Now more than ever, we need to carefully consider specific device characteristics in the context of an individual patient's situation. With increasing use of TAVR, patients undergoing surgical aortic valve replacement are getting younger. More young patients prefer to avoid anticoagulation, at the cost of reduced durability, and choose a bioprosthesis rather than a mechanical prosthesis. It is critical that we educate them about that decision, but it is even more important that we provide them with optimal hemodynamic efficiency.

The most hemodynamically efficient valve not only allows an active patient to resume high-intensity activities but also allows the option of later valve-in-valve TAVR 
and may also translate into better durability, as shown by Johnston and colleagues ${ }^{4}$ in a review of 12,569 replacements performed at Cleveland Clinic. That study found patient-prosthesis mismatch and higher postoperative transvalvular gradients to be strongly associated with valve degeneration, particularly in younger patients. ${ }^{4}$ Average peak and mean gradients in that series were $26 \mathrm{~mm} \mathrm{Hg}$ and $14 \mathrm{~mm} \mathrm{Hg}$, respectively, higher than the average gradients of either valve in the article by D'Onofrio and colleagues $^{3}$ (22/12 mm Hg for Perceval vs 20/10 mm Hg for Intuity). ${ }^{3}$ These easier-to-use valves do not compromise hemodynamic performance and may even enhance it. More follow-up will demonstrate whether this also translates to better durability than the standard surgical bioprostheses.

One of the biggest criticisms of TAVR has been high risk for permanent pacemaker implantation. In a recent review of 35,500 patients undergoing TAVR, complete heart block occurred in more than $10 \%$, with an increasing trend. ${ }^{5}$ Because of the mechanism of fixation, self-anchoring valves have raised similar concern; however, the data from D'Onofrio and colleagues ${ }^{3}$ demonstrated a $6 \%$ occurrence of pacemaker placement for each group in a relatively high-risk population. In comparison, Robich and colleagues ${ }^{6}$ reviewed data from 659,692 patients undergoing surgical aortic valve replacement and found the need for permanent pacemaker placement to be $5 \%$.

Ease of use is an important part of prosthesis choice, particularly if it facilitates less-invasive approaches; however, other critically important characteristics that have been demonstrated to correlate with patient outcomes should not be compromised. More longitudinal data will be needed, but for now, it appears that these new selfanchoring aortic valves facilitate surgical excision and replacement of the diseased aortic valve in fewer steps, thus facilitating less-invasive approaches while maintaining and perhaps improving patient outcomes.

\section{References}

1. Suri RM, Javadikasgari H, Heimansohn DA, Weissman NJ, Ailawadi G, Ad N, et al. Prospective US investigational device exemption trial of a sutureless aortic bioprosthesis: one-year outcomes. J Thorac Cardiovasc Surg. 2019;157: 1773-82.e3.

2. Barnhart GR, Accola KD, Grossi EA, Woo YJ, Mumtaz MA, Sabik JF, et al; TRANSFORM Trial Investigators. TRANSFORM (Multicenter Experience With Rapid Deployment Edwards INTUITY Valve System for Aortic Valve Replacement) US clinical trial: performance of a rapid deployment aortic valve. J Thorac Cardiovasc Surg. 2017; 153:241-51.e2.

3. D’Onofrio A, Salizzoni S, Filippini C, Tessari C, Bagozzi L, Messina A, et al. Surgical aortic valve replacement with new-generation bioprostheses: sutureless versus rapid-deployment. J Thorac Cardiovasc Surg. 2020;159: 432-42.e1.

4. Johnston DR, Soltesz EG, Vakil N, Rajeswaran J, Roselli EE, Sabik JF III, et al. Long-term durability of bioprosthetic aortic valves: implications from 12,569 implants. Ann Thorac Surg. 2015;99:1239-47.

5. Al-Ogaili A, Fugar S, Okoh A, Kolkailah AA, Al Hashemi N, Ayoub A, et al. Trends in complete heart block after transcatheter aortic valve replacement: a population based analysis. Catheter Cardiovasc Interv. February 21, 2019 [Epub ahead of print].

6. Robich MP, Schiltz NK, Johnston DR, Mick S, Krishnaswamy A, Iglesias RA, et al. Risk factors and outcomes of patients requiring a permanent pacemaker after aortic valve replacement in the United States. J Card Surg. 2016;31:476-85. 